\title{
Interfaces
}

\section{Les éditions d'art FMA : la bibliophilie contemporaine se réinvente}

\section{Françoise Maréchal-Alligand}

\section{(2) OpenEdition}

1 Journals

Édition électronique

URL : https://journals.openedition.org/interfaces/2869

DOI : 10.4000/interfaces.2869

ISSN : 2647-6754

Éditeur :

Université de Bourgogne, Université de Paris, College of the Holy Cross

\section{Édition imprimée}

Date de publication : 12 juillet 2021

ISSN : 1164-6225

\section{Référence électronique}

Françoise Maréchal-Alligand, "Les éditions d'art FMA : la bibliophilie contemporaine se réinvente ", Interfaces [En ligne], 45 | 2021, mis en ligne le 12 juillet 2021, consulté le 17 septembre 2021. URL : http://journals.openedition.org/interfaces/2869 ; DOI : https://doi.org/10.4000/interfaces.2869

Ce document a été généré automatiquement le 17 septembre 2021.

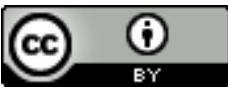

Les contenus de la revue Interfaces sont mis à disposition selon les termes de la Licence Creative Commons Attribution 4.0 International. 


\title{
Les éditions d'art FMA : la bibliophilie contemporaine se réinvente
}

\author{
Françoise Maréchal-Alligand
}

1 Classé dans la catégorie des beaux livres, le livre d'artiste est un espace de dialogue entre littérature et œuvres originales. Ces œuvres artistiques et littéraires qui enchantent les personnes amoureuses des arts, se lisent, se feuillettent, se déplient, s'exposent pour être admirées ou se gardent précieusement, intimement dans leur écrin comme un petit trésor, un bijou. Ces œuvres étant par définition rares (tirage limité à peu d'exemplaires) et précieuses (enluminées), la maison d'édition FMA a souhaité les rendre accessibles par des vidéos (lecture par les auteurs eux-mêmes et feuilletage) en ligne sur editionsdartfma.com avec la volonté affirmée de proposer à un plus large public une autre façon de découvrir la bibliophilie contemporaine, trop restreinte à ce jour aux initiés. Créées en 2008, les éditions d'art FMA ont édité une trentaine d'œuvres présentées dans cet article et une nouvelle édition originale parue à l'automne 2020.

2 Arts plastiques et poésie tiennent une place essentielle dans la vie de Françoise Maréchal-Alligand (initiales FMA de sa maison d'édition). Baudelaire, Reverdy, Cocteau, Char... Mais aussi, Butor, Emaz, Noël... sont parmi ses compagnons de chevet. Elle aspire à développer, créer un lieu où se rencontrent ces deux arts. C'est naturellement dans la bibliophilie contemporaine qu'elle trouve la parfaite illustration de ses aspirations. Elle se nourrit de ses rencontres avec les poètes et les artistes en osmose avec eux, elle développe des œuvres littéraires et iconographiques d'une qualité raffinée, appréciées des bibliophiles et amateurs éclairés. Elle choisit la forme artistique spécifique du livre d'artiste, lieu de partage et d'échange entre un écrivain, un artiste et l'éditeur. Un trio qui dialoguera tout au long de la réalisation du livre afin d'aboutir à un équilibre particulièrement recherché entre texte et image. (Fig. 1) 
Figure 1. Françoise Maréchal-Alligand, éditrice de FMA.

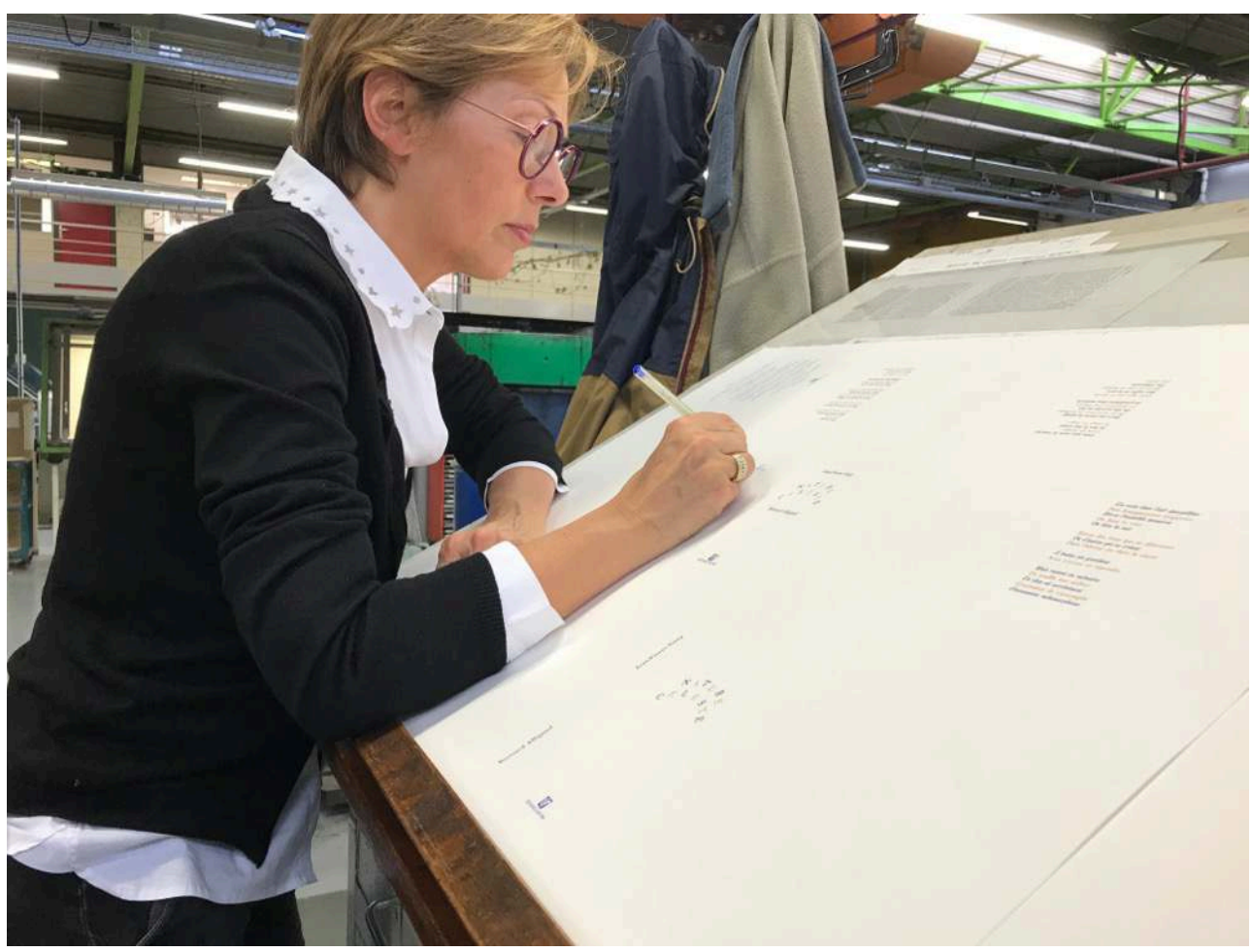

(c) FMA

3 Pour renouveler ce genre, Françoise Maréchal-Alligand choisit d'éditer des poèmes inédits d'auteurs vivants enluminés d'iconographies entièrement originales en privilégiant le savoir-faire des artisans du livre. Tradition, audace et créativité contemporaine caractérisent les Éditions d'art FMA. (Fig. 2) 
Figure 2. Le logo des Éditions d'art FMA.

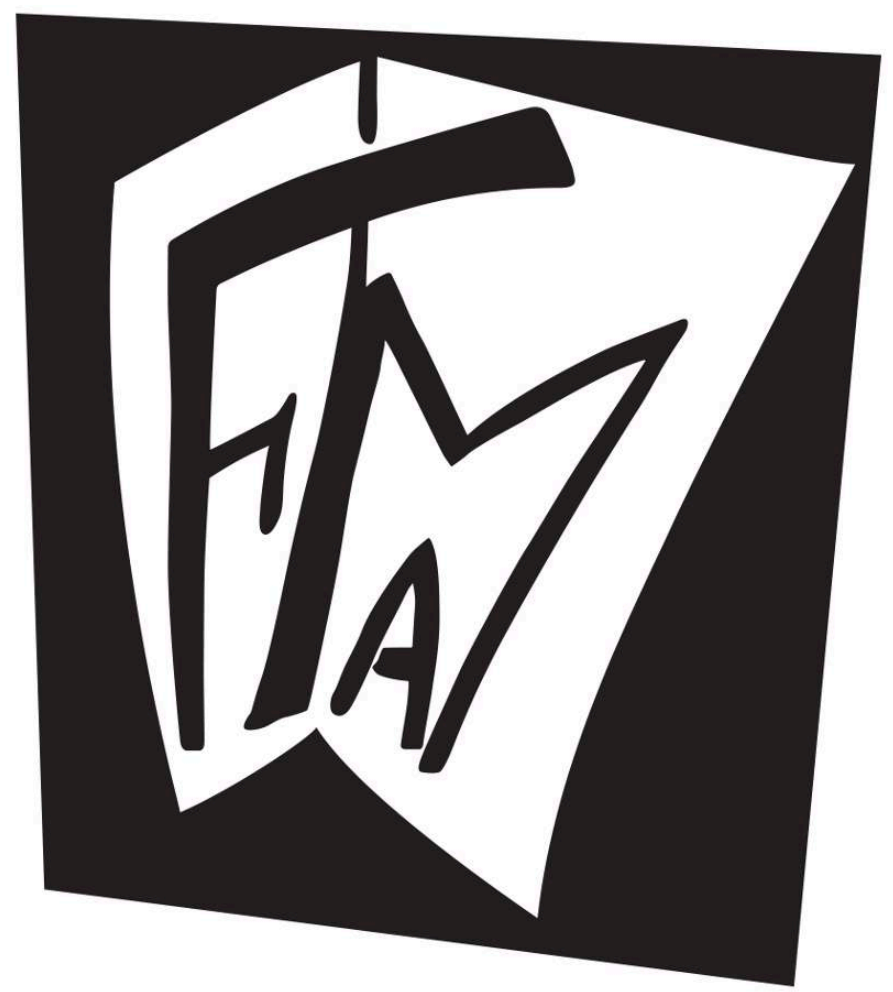

(c) FMA

4 En 2008, pour son premier livre d'artiste, elle s'appuie sur la complicité de Michel Butor et son époux Bernard Alligand qui tous deux ont réalisé plusieurs livres ensemble.

Ce fut une joie immense lorsque Michel Butor, «monument» de la littérature française, accepta de collaborer avec moi et qu'il me proposa le poème La restauration du corps féminin (Fig. 3) ${ }^{1}$. Sa bienveillance, sa stature d'écrivain étaient un véritable fer de lance pour les éditions d'art FMA. J'ai eu envie de me plonger dans La modification, emblématique, qui le fit connaitre du grand public (Prix Renaudot 1957) et encore aujourd'hui des lycéens, et Passage à Milan qui précéda La modification, ainsi que sa poésie que je connaissais peu. 
Figure 3. Michel Butor et Bernard Alligand, La restauration du corps féminin (2008).

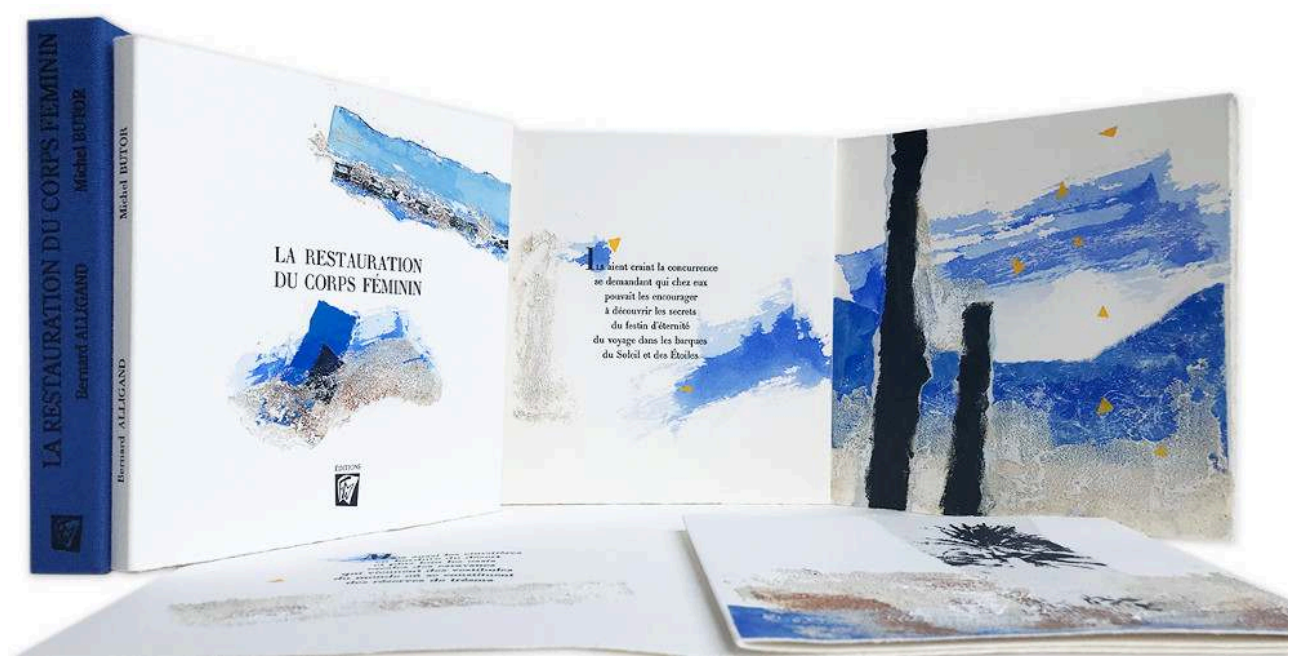

Poème inédit accompagné d'œuvres originales : sujets photographiés, numérisés, retouchés, imprimés sur papier peint par l'artiste, aquarelle et estampage de sable du désert libyen, rehaut des lettrines sur chaque page. Edition originale à 45 ex. numérotés, signés par l'auteur et l'artiste. Livre en double feuillet, form. carré $15 \mathrm{~cm}, 28$ p. plus couverture, texte composé à la main en caractère Marcellin-Legrand, tiré sur Vélin BFK Rives $270 \mathrm{~g}$. par l'atelier du Livre d'art de l'Imprimerie nationale (emboitage)

(c) FMA

Parallèlement, Françoise Maréchal-Alligand rencontre Christian Jourdain, directeur de l'atelier du livre d'art et de l'estampe de l'Imprimerie nationale. Soucieuse de la qualité de ses éditions, elle souhaite bénéficier du savoir-faire des artisans du livre qui détiennent de solides compétences dans le domaine de la chaîne typographique. C'est lors de ses visites à l'atelier à Ivry-sur-Seine qu'elle découvre le patrimoine unique au monde des poinçons dont la grande partie est classée monument historique. Et parmi les poinçons, les 7 caractères latins exclusifs de l'Imprimerie nationale : Garamont de François $1^{\mathrm{er}}$, Grandjean ou Romain du Roi, Jaugeon de Louis XIV, Luce de Louis XV, Didot millimétrique de Napoléon $1^{\mathrm{er}}$, Marcellin-Legrand et Gauthier.

6 Au fil de ses éditions, Françoise Maréchal-Alligand aura une préférence pour l'esthétisme du graveur-inventeur Louis Gautier en 1950 : "Je voulais faire pour notre époque un caractère auquel je souhaitais donner des qualités de lisibilité, de simplicité et de clarté (citation de Louis Gautier). J'ai utilisé le Gautier, notamment pour Zone grise d'Antoine Emaz (Fig. 4) ${ }^{2}$. Sa ligne répondait bien à son écriture épurée exprimant avec force la tension du quotidien. " 
Figure 4. Antoine Emaz et Bernard Alligand, Zone grise (2013).

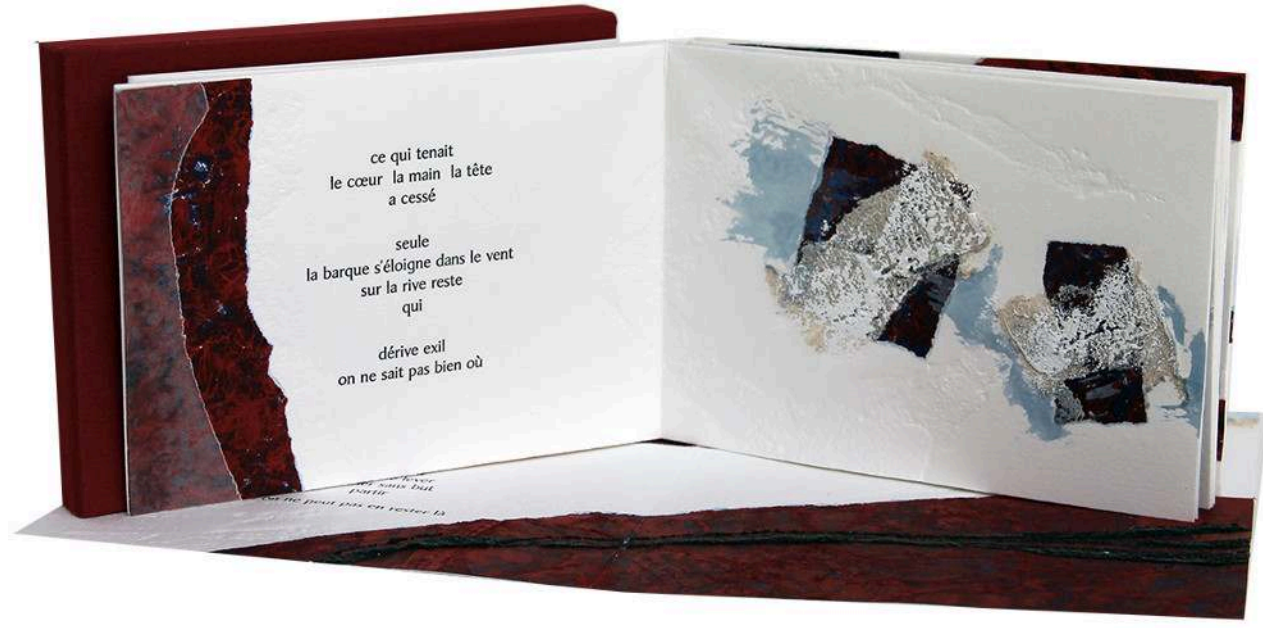

Poème inédit accompagné d'œuvres originales : collage de papier peint par l'artiste et calque. Estampage selon la technique de gravure au carborundum, rehauts de sable, d'aquarelle et d'acrylique. Édition originale à 45 ex. numérotés, signés par l'auteur et l'artiste. Livre en double feuillet, form. $12,5 \times 16,5 \mathrm{~cm}, 24$ p. plus couverture. Texte composé à la main en caractère Gauthier, tiré sur Vélin BFK Rives $250 \mathrm{~g}$. par l'atelier du Livre d'art de l'Imprimerie nationale (emboîtage). (c) FMA

7 Chaque édition sera présentée dans un écrin, pour sa protection mais aussi pour sa mise en valeur, sobre et élégante. Pour ses deux premières éditions, l'éditrice dessine un coffret qu'elle fait réaliser par l'atelier Dermont-Duval, reconnue sur le marché de la reliure-emboîtage comme ayant su allier tradition, modernité et qualité. Puis elle fait travailler l'atelier d'artisanat d'art Paxion, entreprise familiale passionnée qui réalise les coffrets et étuis des éditions suivantes. Mais la rareté a aussi un prix. L'atelier Paxion a définitivement arrêté son activité l'été 2019. Aujourd'hui la Reliure du Centre à Limoges prend le relais.

\section{La restauration du corps féminin, premier livre d'artiste des éditions d'art FMA}

8 Michel Butor y revisite le fameux mythe d'Isis et Osiris en inversant les rôles entre le dieu et la déesse.

Depuis il parcourt l'Égypte / non seulement le Delta / et la Vallée tous leurs champs / qui émergent lentement / dans l'abaissement du Nil / les îles de leurs villages / réfléchies par son miroir.

Le poème inédit est enluminé des œuvres originales de l'artiste Bernard Alligand. «Réaliser des œuvres originales, uniques, sur chaque exemplaire de l'édition (45 à 50 exemplaires), est un challenge que peu d'artistes peuvent relever. L'œuvre de bibliophilie de Bernard, aujourd'hui composée de plus d'une centaine de livres d'artiste conservés dans la réserve patrimoniale de la bibliothèque Toussaint à Angers, m'apportait un gage de créativité, d'audace et de qualité de réalisation sur lequel je me suis appuyée en toute confiance ». Dans son coffret entoilé bleu, ce premier livre (2008) est une merveilleuse invitation à rêver. Les lettrines rehaussées par des touches bleutées à l'aquarelle, les collages, l'estampage de sable ramassé dans le désert libyen 
ouvrent un champ imaginaire infini. «Michel Butor a composé ce poème en strophes d'une régularité parfaite. Il m'a inspiré un format carré, intime par sa taille $15 \times 15 \mathrm{~cm}$. Un carré que j'ai décliné $(18 \times 18 \mathrm{~cm}, 19 \times 19 \mathrm{~cm}$...) pour la majeure partie de mes éditions, en leporello ou feuillets. Il a l'avantage d'offrir un espace équilibré et une grande liberté dans la mise en pages ». Puis, le choix du caractère au plomb du livre est également une étape importante. "J'ai retenu le caractère Marcellin-Legrand (créé vers 1836) pour son style qui m'évoquait l'Orient. J'ai été surprise qu'un an après l'édition de La restauration du corps féminin, Franck Jalleau, créateur de caractères typographiques de l'atelier du livre d'art et de l'estampe, en ait fait une version numérique, baptisée Le Maghrébin. »

Les principes de la ligne éditoriale des éditions d'art FMA sont ainsi posés: textes inédits de poètes contemporains, généreusement enluminés d'œuvres originales, caractères typographiques en plomb, petit tirage signé par l'auteur et l'artiste, format intimiste, papier d'art ayant une bonne main, façonnage soigné et coffret entoilé pour la présentation.

11 La restauration du corps féminin sera présenté fin 2011 par l'Imprimerie nationale, invitée du Grolier Club de New York pour une exposition intitulée « Printing for Kingdom, Empire and Republic, Treasures of the Archives of the Imprimerie Nationale ». Près de 200 pièces majeures, dont la plus grande partie est classée monument historique, sont exposées, comprenant manuscrits originaux, livres anciens et livres de bibliophilie, estampes, poinçons et matrices datant du XVI ${ }^{\mathrm{e}}$ siècle à nos jours.

\section{«Carré d'Éros », pour éveiller nos sens}

Début 2008, l'éditrice visite l'exposition l'Enfer organisée par la Bibliothèque nationale de France. Textes, croquis, essais, romans ou manuscrits au format minuscule, photographies... invitent à un voyage à travers des siècles de littérature érotique. Sont exposés les écrits de Baudelaire, Apollinaire, Sade, Bataille et bien d'autres. Envisager une collection sur ce thème? Elle l'intitulera "Carrés érotiques » puis " Carré d'Éros » et choisit UNE poète pour la première édition. Tita Reut lui propose Le Ring (Fig. 5) ${ }^{3}$. D'un érotisme débridé, le poème met en scène une femme libre guidant son partenaire dans leurs plaisirs charnels. Attiré par un jeu de matières et de transparences, d'entrelacements des couleurs rouge et noire, le regard caresse les courbes féminines, explicites, des œuvres de Bernard Alligand.

Arrache le sommeil / de mon chaos / Je vais résister / par la force / d'une croisade volontaire / étonnée du sexe / brûlée au bleu / rampée / sous la balle au centre. 
Figure 5. Tita Reut et Bernard Alligand, Le Ring (2008).

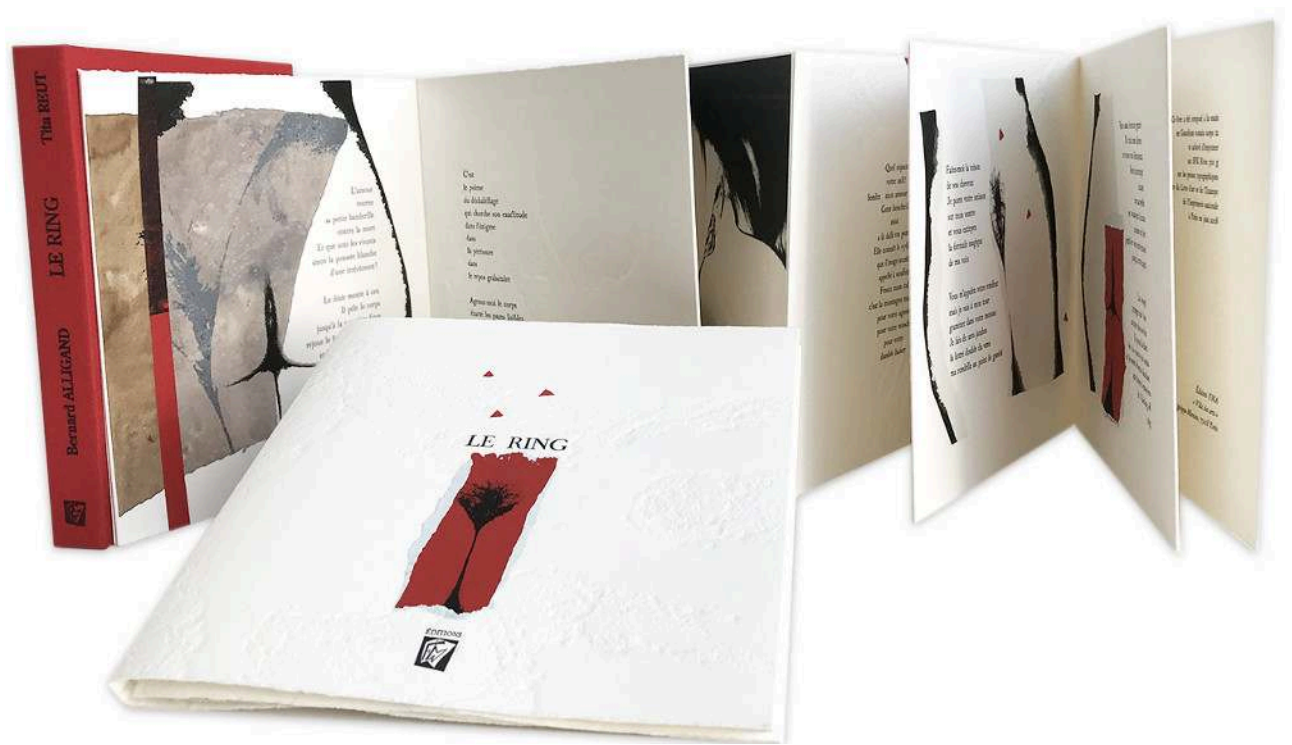

Poème inédit accompagné d'œuvres originales : sujets photographiés, numérisés, retouchés, imprimés sur papier peint par l'artiste et calque. Estampage selon la technique de gravure au carborundum et rehaut à la gouache. Édition originale à 45 ex. numérotés, signés par l'auteure et l'artiste. Leporello form. carré $19 \mathrm{~cm}, 12$ volets plus couverture (2,3 mètres à plat), texte composé à la main en caractère Romain du Roy, tiré sur Vélin BFK Rives 300 g. par l'atelier du Livre d'art de I'Imprimerie nationale (emboîtage).

(c) FMA

Au printemps 2009, Anne-Gaëlle Lebouc de la librairie Les Arcades à Paris présentera les deux premiers ouvrages des éditions d'art FMA pour dédicace en présence des auteurs et de l'artiste.

14 En 2010, Gaston Puel compose à son tour un poème érotique (Fig. 6) ${ }^{4}$. " J'ai été profondément émue à la lecture du poème de Gaston! Une ode à l'amour par-delà le temps qui passe, par-delà la maladie d'Alzheimer de son épouse, décédée. Au fil de l'édition et des relectures, il changeait quelques mots, sa poésie évoluait. Cela a été une aventure touchante nourrie d'une importante correspondance. Ce poème est une merveille».

L'air que je respire / Le jour qui nous voit / Étreintes nature que rien ne fourvoie...

/ Cri de l'alouette / Ciel, lait de clartés / Dolente tendresse / Tout s'est écoulé / Tes épaules d'ombre brûlées / M'envoûtent encore et m'invitent. 
Figure 6. Gaston Puel et Bernard Alligand, Terre d'ombre brûlée (2010).

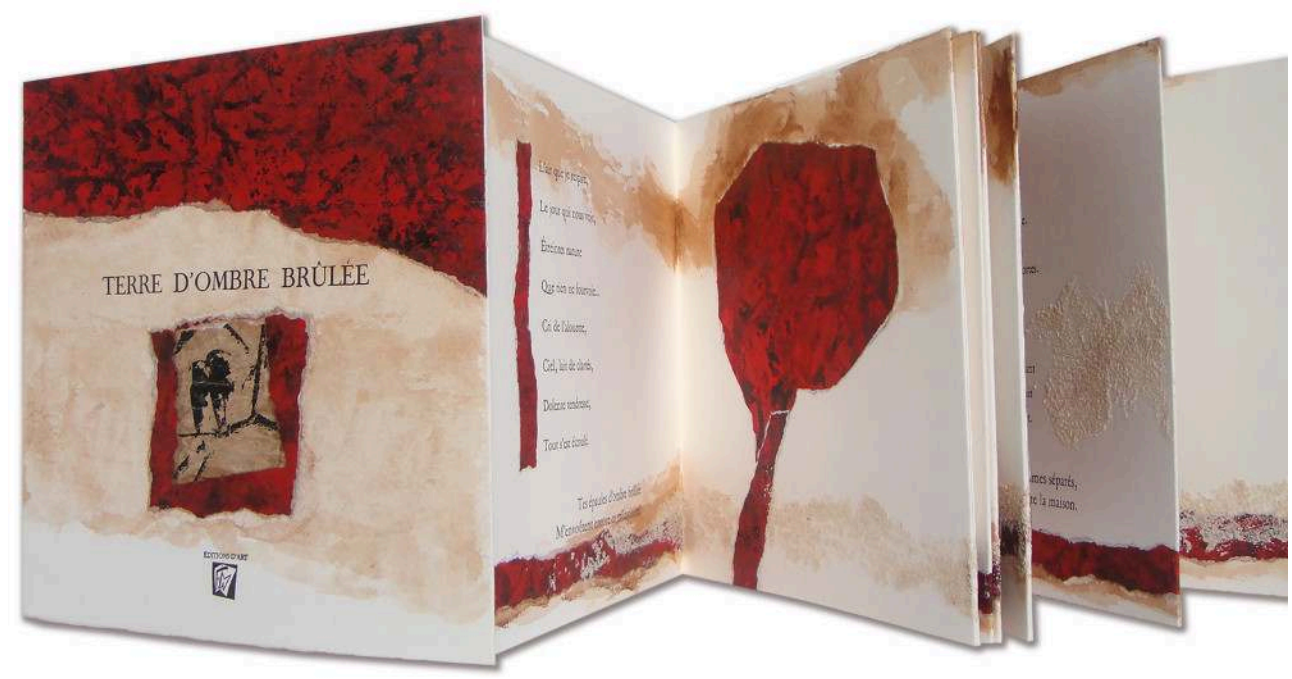

Poème inédit accompagné d'œuvres originales : sujets photographiés, numérisés, retouchés, imprimés sur papier peint par l'artiste, déchirures, rehaut de sable, aquarelle, encre. Édition originale à 45 ex. numérotés, signés par l'auteur et l'artiste. Leporello form. carré $19 \mathrm{~cm}$, 18 volets (3,4 m à plat), texte composé à la main en caractère Garamont, tiré sur Vélin BFK Rives 300 g. par l'atelier du Livre d'art de l'Imprimerie nationale.

(c) FMA

La bibliothèque littéraire Jacques Doucet en a fait l'acquisition avec son manuscrit et la correspondance qui l'entoure. La bibliothèque constitue la collection la plus riche au monde pour ce qui est de la littérature française, de Baudelaire à nos jours. Elle se compose de 90 fonds d'écrivains dont Mallarmé, Verlaine, Apollinaire, Reverdy, Char, Éluard, Malraux, Bernard Noël, pour n'en citer que quelques-uns.

En 2011, l'éditrice continuera sur sa lancée en sollicitant Régine Detambel. Les ouvrages de Régine Detambel interrogent le corps et sa mémoire, au travers des expériences sensibles de la détresse et de la maladie, et font du processus de guérison un moteur romanesque. "Régine a une écriture 'bienfaitrice' et 'corporelle'. Ravigote est une promenade hédoniste à la sauce ravigote pour éveiller nos sens. » (Fig. 7) ${ }^{5}$

Mon corps est une plante / que la terre a faite / pour donner un nom au désir / Je fais du bruit en te mangeant / j'ai l'énorme convoitise des racines / je suis une racine de mélèze qui plonge.

C'est dans une douce suggestion que l'auteur et l'artiste concoctent leur recette bucolique et sensuelle à la sauce ravigote : le « toucher » par le velouté des matières, la « vue » par les courbes suggestives, l'« odorat " par le mélange d'ingrédients... Ravigote paraît en 2012, et la même année, Rituel des sens de Sigurður Pálsson (Fig. 8) ${ }^{6}$. Un volume aux tonalités froides comme les côtes islandaises où la nature réveille les émois

Sentir le bruissement / sentir l'écume monter / sentir la fontaine frémir / Sentir le sang tourner / sentir les vagues violentes / brisée sur les récifs. 
Figure 7. Régine Detambel et Bernard Alligand, Ravigote (2012).

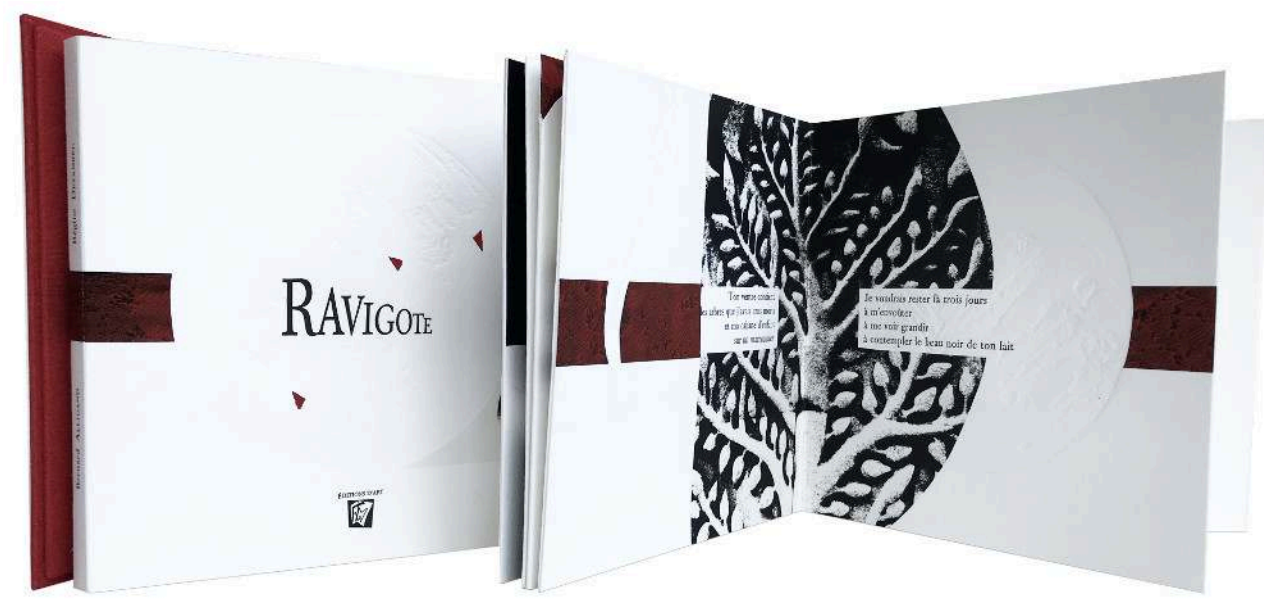

Poème inédit accompagné d'œuvres originales : sujets photographiés, numérisés, retouchés, imprimés sur papier peint par l'artiste. Estampage selon la technique de gravure au carborundum, rehauts au pochoir de pigments pourpre, noir et doré. Édition originale à 45 ex. numérotés, signés par l'auteure et l'artiste. Leporello form. carré $19 \mathrm{~cm}$, 16 volets ( $3 \mathrm{~m}$ à plat), texte composé à la main en caractère Granjean, tiré sur Vélin BFK Rives 300 g. par l'atelier du Livre d'art de l'Imprimerie nationale. (c) FMA

Figure 8. Sigurður Pálsson et Bernard Alligand, Rituel des sens (2012).



Poème inédit accompagné d'œuvres originales : sujets photographiés, numérisés, retouchés, imprimés sur papier peint par l'artiste, collage. Estampage selon la technique de gravure au carborundum, rehaut à la gouache. Édition originale à 45 ex. numérotés, signés par l'auteur et l'artiste. Livre en double feuillet de 28 p. plus couverture, form. carré $15 \mathrm{~cm}$, texte composé à la main en caractère Baskerville, tiré sur Vélin BFK Rives 250 g. par l'atelier du Livre d'art de l'Imprimerie nationale (emboîtage).

(c) FMA 


\section{Ruines d'avenir, le livre aux 7 artistes}

182013 marque un tournant dans les Éditions d'art FMA avec un projet d'envergure qui associe sept signatures, une par volume, pour constituer le coffret Ruines d'avenir (Fig. 9) 7 .

Fasciné par la monumentale tenture médiévale de l'Apocalypse du château d'Angers, Michel Butor a composé une réinterprétation poétique et critique des lettres envoyées par Saint Jean aux sept églises de L'Apocalypse. Cette nouvelle apocalypse intitulée Ruines d'avenir est empreinte d'une tension créatrice paradoxale : d'un avenir en ruines émergera l'avenir. Testament autant que credo de cet auteur prolifique allant sur ses quatre-vingt-dix-ans, Ruines d'avenir propose une illustration par le verbe et l'image de l'ambivalence des deux acceptions de l'Apocalypse : à la fois catastrophe et révélation. Ce poème, composé de sept épîtres de sept strophes, de sept vers, de sept syllabes, a été édité en sept livres d'artistes, un par épîtres. Première épître, Ephèse :

Chers amis je vous écris / depuis l'île de Patmos / pour vous donner du courage / et pour vous réconcilier / c'est la crise de l'église / tout se fend de toutes parts / mais il faut tenir le coup...

Figure 9. Michel Butor et Bernard Alligand, Patricia Erbelding, Bertrand Dorny, Anne Walker, Maxime Godard, Gérard Eppelé, Ruines d'avenir (2013).



Texte inédit enluminé de compositions originales de chaque artiste dont le poète. L'ouvrage recouvre une multitude de techniques : gravure au carborundum, photographie, textile, carte postale, sable, pastel, aquarelle, gouache, acrylique, mine de plomb, fusain, sanguine, feutre, encre. Édition originale à 12 ex., 2 HC. Chaque exemplaire est numéroté et signé au colophon par l'auteur et l'artiste. 7 leporellos, form. carré $18 \mathrm{~cm}$, déplié de $3 \mathrm{~m}$ chacun. Texte composé en caractère Garamont, tiré sur Moulin du Gué 270 g. par le Groupe Prenant (emboîtage).

(c) FMA 

d'interventions originales de l'auteur et de six de ses amis plasticiens, peintres et photographes. Ephèse : Bernard Alligand utilise la technique au carborundum pour l'estampage dans le blanc du papier et des collages pour faire surgir de fiers cavaliers. Tout en transparence et opacité. Smyrne : Patricia Erbelding esquisse à la sanguine un cheval rouge; et par l'usage de la cire d'abeille fait apparaître/disparaitre les traces supposées de l'animal, lui-même disparu de la tenture. Pergame: Bertrand Dorny reprend la matière textile en collant des tissus japonais. Thyatire : Anne Walker adopte l'esprit des enluminures avec des filets et des cartouches irisés au pastel. Sardes: Maxime Godard convoque les animaux préhistoriques pour créer un bestiaire fantastique. Philadelphie : Gérard Eppelé s'intéresse aux anges, qu'il dessine avec une technique différente pour chaque exemplaire (aquarelle, encre de couleur, crayon à mine de plomb, etc). Enfin, Laodicée: Michel Butor appose ses collages sur une alternance d'encre rouge et bleue pour reprendre le rythme de la tenture. "Michel a repris l'idée de sa riche correspondance avec les artistes et amis, les fameuses lettres-collage. "

nourrissant autant du texte biblique que de la tapisserie d'Angers, les artistes accompagnent chacun une épître de leurs gravures, collages, dessins ou photographies. Entre les dominantes de rouges infernaux et de bleus célestes, entre transparence et opacité, ils aspirent à recoller les morceaux de nos drames, à restaurer nos ruines. Du monde de la tenture d'où viennent trompettes, anges, cavaliers et cités, un monde nouveau apparaît.

S'inspirant de la lecture ambulatoire de la tapisserie du château d'Angers, l'éditrice Françoise Maréchal-Alligand fait le choix d'une édition en livres dépliants. Chaque volume se déploie en un leporello de dix-sept volets dont les trois derniers servent de couverture et de rabat, en face de la page de titre. Sur chacun des sept livres, quatorze volets sont laissés au texte et aux œuvres plastiques, comme sur chacune des grandes pièces de la tapisserie médiévale. Chaque exemplaire, long d'un peu plus de trois mètres, dépasse de peu la largeur moyenne d'une scène de la tapisserie, tandis que la série complète approche, avec ses 21,42 mètres, la longueur présumée de chaque grande pièce de la tenture de l'Apocalypse.

23 «Édité à très peu d'exemplaires, dès l'initiation du projet, il était question de mettre en lumière la genèse et la symbolique de Ruines d'avenir à travers une exposition itinérante, des vidéos... et un catalogue publié par les éditions Actes sud et la Ville d'Angers. » L'ouvrage de bibliophilie sera exposé au château d'Angers de mars à fin août 2016, puis à la bibliothèque Louis Nucéra de Nice en hiver 2017 et à la bibliothèque Ceccano d'Avignon l'été 2018. Le poème est repris sous la forme d'un fac-similé des sept volumes agrémenté d'introductions à cette œuvre littéraire et plastique de Mireille Calle-Gruber, romancière, professeur de littérature française et comparée à l'université Sorbonne Nouvelle-Paris 3, de Marc-Édouard Gautier, archiviste-paléographe, conservateur en chef des bibliothèques et directeur adjoint de la bibliothèque municipale d'Angers et de Patricia Corbett, docteur en histoire de l'art du Moyen Âge, administratrice du château d'Angers, ainsi que de commentaires de leurs interventions par chacun des artistes.

Plusieurs vidéos ont été mises en ligne sur la chaîne YouTube des éditions d'art FMA : une interview par Mireille Calle-Gruber, de Michel Butor, Bernard Alligand et Françoise Maréchal-Alligand qui présente la genèse du projet, un reportage sur l'inauguration de 
l'exposition au château d'Angers, la lecture par Michel Butor des 7 poèmes avec feuilletage des livres.

\section{La Dame à la licorne : double regard, masculin, féminin}

Forte de cette aventure collective, Françoise Maréchal-Alligand désire réaliser un nouvel ouvrage inspiré d'une tapisserie emblématique : "Avec Bernard, nous avons cherché une autre tenture inspirante, mais cette fois-ci profane. " La Dame à la licorne du musée de Cluny s'impose. Le toucher, le goût, l'odorat, l'ouïe et la vue... Ces six tapisseries, tissées autour de 1500, représentent les cinq sens sur un fond rouge habité d'une nature foisonnante. Reste le sixième sens, énigmatique. Ces tapisseries de style «millefleurs » se caractérisent par une flore abondante (fleurs, orangers, pins, houx, chênes) et sont peuplées d'un bestiaire paisible (singe, chiens, lapins, héron). Dans cette nature paradisiaque qui invite à la contemplation, la licorne est tantôt actrice et tantôt simple spectatrice. Accompagnée d'un lion, la tapisserie porte sur chaque scène les armoiries de la famille Le Viste. La tenture de la Dame à la licorne a été acquise en 1882 par l'État sur la recommandation de Prosper Mérimée, inspecteur de monuments nationaux. Elle est aujourd'hui considérée comme l'un des grands chefs d'œuvre de l'art occidental. "C'est un hymne à la féminité qui touche des réalités universelles. J'ai donc confié le premier volume, dont le titre est Aux jardins de la licorne, à un binôme masculin, Michel Butor et Bernard Alligand, et le second à un binôme féminin, Régine Detambel et Patricia Erbelding, qui a imaginé Elle est le monde. " Le coffret sorti en 2015 présente ces deux livres en vis-à-vis (Fig. 10) ${ }^{8}$. L'animal fabuleux offre sa silhouette énigmatique dans un jeu de positif/négatif. Les couvertures se répondent étonnamment, sans concertation entre les artistes et auteurs, les projets ayant été menés de façon indépendante par Françoise Maréchal-Alligand.

Figure 10. Régine Detambel et Patricia Erbelding, Elle est le monde (2015).

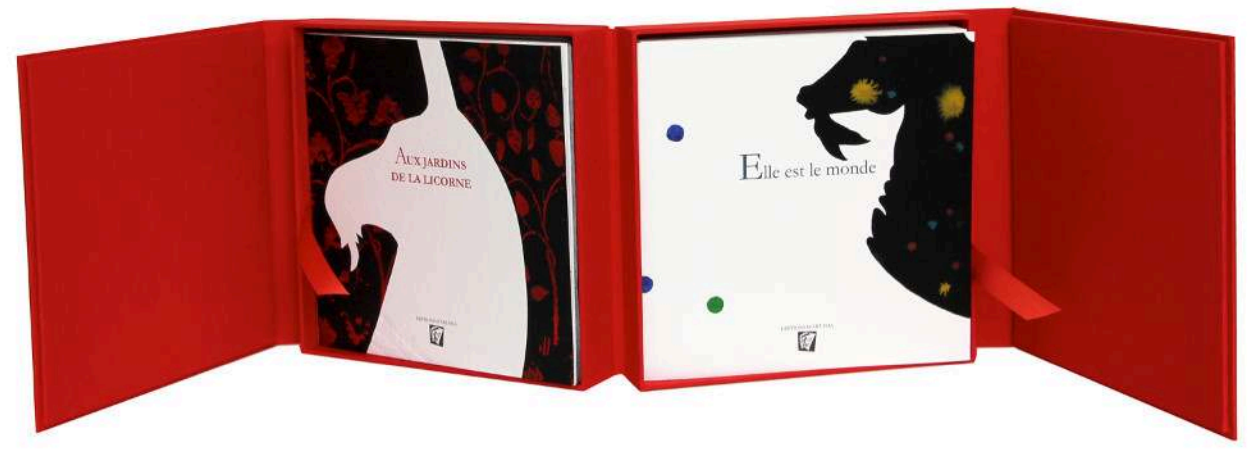

Interprétation des décors floraux de la Dame à la licorne en lavis aquarellé de multiples couleurs et estampage de cire créant un effet de transparence sur l'ensemble du livre. Michel Butor et Bernard Alligand, Aux jardins de la licorne (2015). Détails de la tapisserie de la Dame à la licorne photographiés, numérisés, retouchés, tirés sur papier de différentes textures; dessins, peinture acrylique, résine sur calque, collages, découpes, estampage dans le blanc du papier. Édition originale 2015 à 45 ex. numérotés et signés par l'auteur et l'artiste. Leporello. Form. carré $18 \mathrm{~cm}$. 19 volets dont couverture (3,40 m). Texte composé en caractère Garamont, tiré en offset sur Moulin du Gué $270 \mathrm{~g}$ par le Groupe Prenant (emboîtage).

(c) FMA 
26 À l'intérieur surgissent des univers complémentaires : "Les hommes adoptent un parti pris descriptif avec des photographies tirées sur des papiers de textures différentes. »Ces pages sont ennoblies par une grande diversité de techniques qui créent de la profondeur et du mystère : dessin, peinture, calque, résine, découpe, estampage... «Le regard féminin est allégorique. " Il revisite le style millefleurs dans des couleurs vives et fraîches en lavis aquarellé et sublime le poème inspiré de l'amour courtois. Des applications de cire apportent des effets de transparence qui se révèlent à la lumière en dépliant le livre. "Grâce à nos amis Brigitte et Gilles Benoist de l'association des Amis du musée de Cluny, nous avons pu rencontrer la direction du musée pour envisager une présentation de l'ouvrage.» Le duo bibliophilique a été présenté dans le cadre de l'exposition Magique licorne qui inaugurait la réouverture du musée du 14 juillet 2018 au 25 février 2019. Au préalable, une rencontre-lecture a eu lieu le 13 novembre 2017, animée par Béatrice de Chancel-Bardelot, conservateur général du patrimoine au musée de Cluny, Clara Dupont-Monod, journaliste, romancière et spécialiste de la culture médiévale, Mireille Calle-Gruber, Françoise Maréchal-Alligand et d'autres contributeurs.

\section{Un mode collaboratif basé sur la proximité}

"Mon métier d'éditrice consiste à offrir des œuvres artistiques et littéraires capables d'enchanter les personnes amoureuses de la littérature et des beaux livres. Mais personnellement, j'attache beaucoup d'importance à ce que chaque projet soit porteur d'amitié, de joie et de fierté partagée. » Françoise Maréchal-Alligand sollicite les poètes pour leur demander une œuvre exclusive : "En général, je demande plusieurs textes afin d'avoir le choix. Puis je réalise la mise en page en l'adaptant à l'esprit du texte. » Après avoir partagé cette première étape avec l'auteur, les textes sont composés par un artisan de l'édition d'art. " Au moment du tirage (j'y assiste toujours) je demande à l'artisan d'accentuer le foulage du caractère. Au-delà de la sensualité du toucher, le relief qu'il apporte au texte est une façon de prendre le contrepied du numérique de plus en plus utilisé par les éditeurs et/ou artistes. C'est un des éléments de distinction de mes éditions. »

Les réserves de l'atelier du livre d'art et de l'estampe contiennent des trésors que l'éditrice utilise volontiers. Bernard Alligand a ainsi retravaillé le motif impérial de l'abeille pour Hexagones en désarroi de Michel Butor (2012) (Fig. 11) ${ }^{9}$. En faisant parler les abeilles, l'auteur évoque avec lucidité et poésie l'Homme et ses agissements envers ces ouvrières en détresse. Pollen, papier artisanal en feuilles de mûrier, hexagones en relief... les œuvres matiéristes de l'artiste incitent au toucher.

Je ne sais quel poison / s'insinue dans nos veines / nos ailes ralentissent / nos pattes maladroites / ne nous permettent plus / d'amasser le pollen... 
Figure 11. Michel Butor et Bernard Alligand, Hexagones en désarroi (2008).

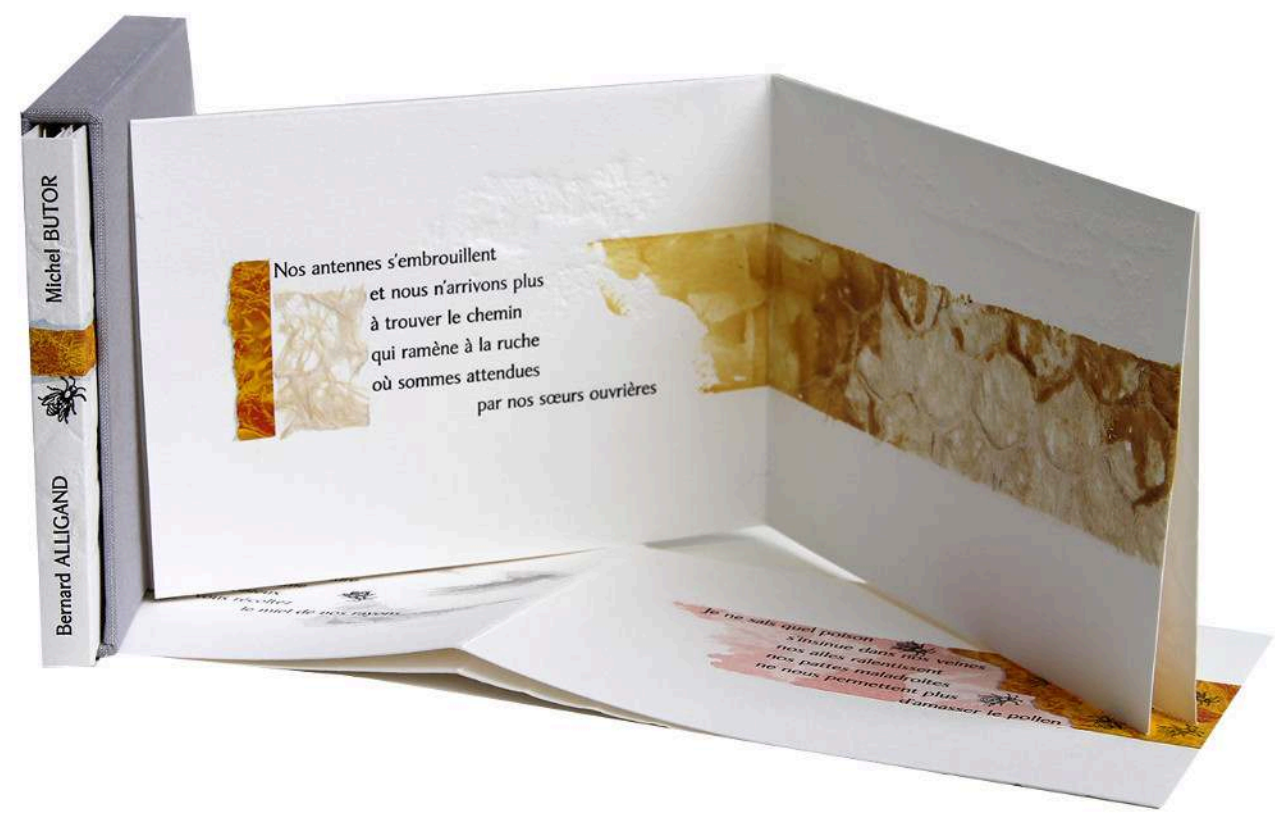

Poème inédit accompagné d'œuvres originales : sujets photographiés, numérisés, retouchés, imprimés sur papier et calque. Estampage selon la technique de gravure au carborundum et rehaut de gouache. Tampon réalisé à partir de l'abeille Napoléon III (collection exclusive de l'Atelier du livre). Édition originale à 45 ex. numérotés, signés par l'auteur et l'artiste. Leporello, form. carré $19 \mathrm{~cm} ., 12$ volets plus couverture (2,3 m à plat). Texte composé à la main en caractère Romain du Roy, tiré sur Vélin BFK Rives 300 g. par l'Atelier du Livre d'art de l'Imprimerie nationale (emboîtage).

(c) FMA

Pour Rivage de Pount (2012), du poète libanais Salah Stétié, un hiéroglyphe différent vient ponctuer chaque strophe (Fig. 12) ${ }^{10}$. «Pour aller jusqu'au bout de l'exercice typographique, le traducteur de l'Imprimerie nationale a créé le titre en hiéroglyphe.» Le Pays de Pount apparaît dans les récits de l'Égypte antique comme un lieu d'échanges et de négoce où les Égyptiens allaient s'approvisionner en denrées rares. Le poème est un dialogue mystérieux entre l'Orient et l'Occident.

Il ne faut pas s'approcher des fenêtres / Elles ouvrent sur le monde / Et le monde, cerné de vols, n'ouvre pas. / Le jour n'est pas levé. / Midi n’a pas bougé. / Le soir n'est pas tombé.

Ce livre d'artiste fait partie de la donation de Salah Stétié au musée Paul-Valéry à Sète. 
Figure 12. Salah Stétié et Barnard Alligand, Rivage de Pount (212).

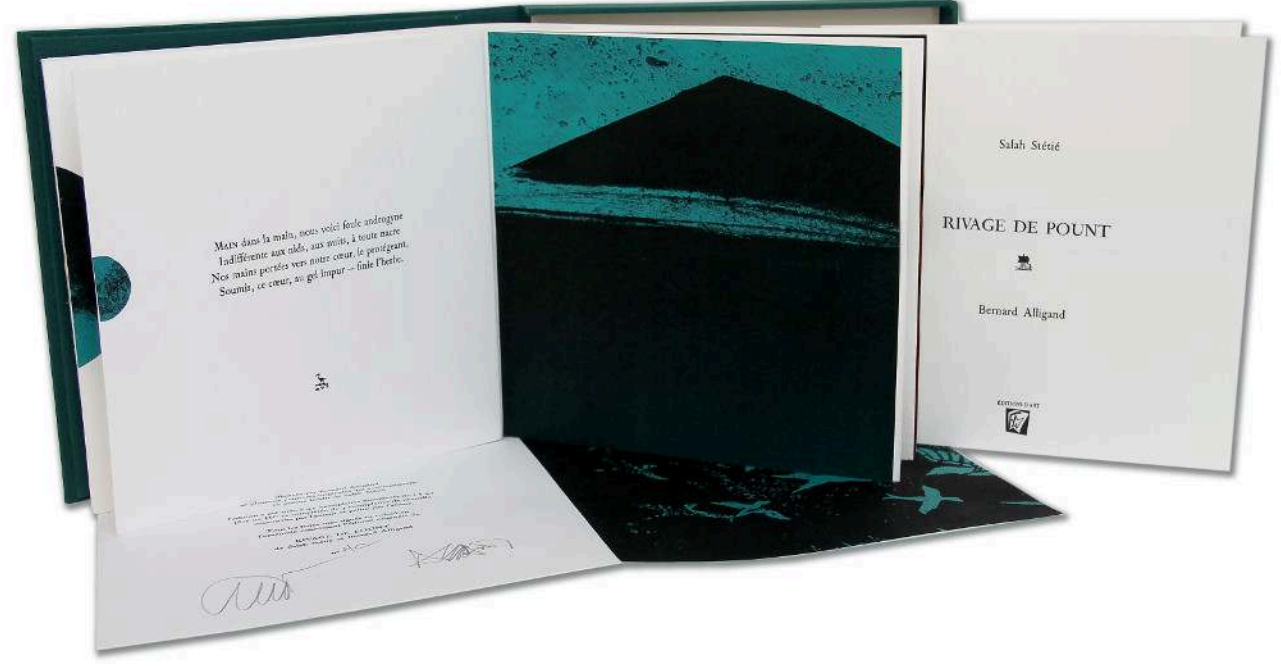

4 poèmes inédits accompagnés d'œuvres originales : sujets photographiés, numérisés, retouchés, imprimés sur papier peint par l'artiste, découpe de papyrus. Hiéroglyphes typographiés et ajout au tampon encré. Édition originale à 45 ex. numérotés, signés par l'auteur et l'artiste. Livre en double feuillet, form. carré $18 \mathrm{~cm}, 32 \mathrm{p}$. plus couverture. Texte composé à la main en caractère Granjean, tiré sur Vélin BFK Rives $300 \mathrm{~g}$. par l'atelier du Livre d'art de l'Imprimerie nationale (emboîtage).

(c) FMA

\section{L'art de la mise en page}

"Je mets au centre de mes éditions, la rencontre et l'amitié, je m'adresse directement aux auteurs et aux artistes. Je choisis le format du livre et le cadencement du poème en fonction de son rythme interne. Ils me donnent leur avis. Ensuite, j'envoie la maquette à l'atelier.» Les artistes interviennent directement sur les pages blanches. Deux sortes de papier d'art sont utilisés pour les éditions d'art FMA : BFK Rives ou Moulin du Gué en 250 ou 300 grammes. "L'épaisseur du support offre plus de liberté aux artistes. J'ai fait ce choix en fonction du travail en matière de Bernard Alligand. »Concernant le coffret Toros (2017), les trois chroniques de Robert Marteau sur les corridas sont déclinées en trois volumes, chacun illustré par un artiste. La mise en page des textes reprend les principaux symboles : arène, cornes du taureau, cape... D'une autre planète par Bernard Alligand, Voyage à Vic par Julius Baltazar et Otro toro par Gérard Eppelé, la suite de Torero blessé (2010) du même auteur, inspiré de l'accident de José Tomàs dans les arènes d'Aguascalientes (Fig. 13) ${ }^{11}$.

L'ange discret qui se tient au balcon / Et veille sur toi fut brièvement distrait. 
Figure 13. Robert Marteau, Toros (2017) : Bernard Alligand, D'une autre planète ; Julius Baltazar, Voyage à Vic ; Gérard Eppelé, Otro toro.

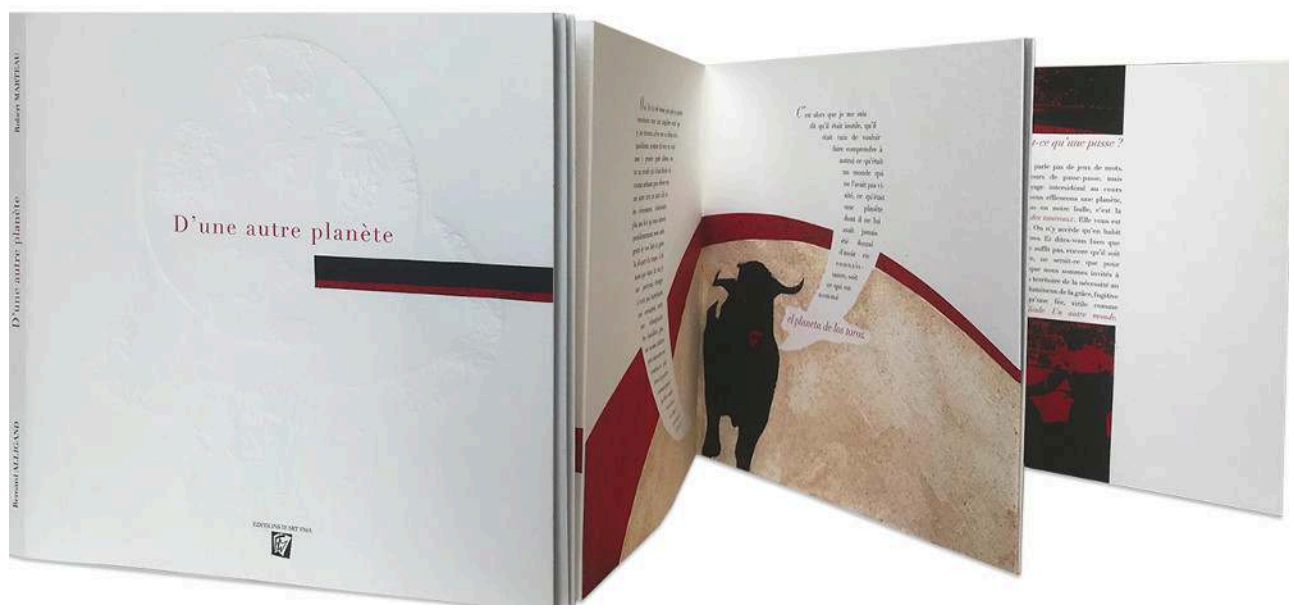

Compositions originales de chaque artiste sur chaque volume. L'ouvrage recouvre plusieurs techniques : gravure au carborundum, photographie, sable, sanguine et fusain, encre, feutre, mine de couleur, gouache... Édition originale à 21 ex. numérotés, signés par l'auteur et l'artiste. Leporello, form. carré $25 \mathrm{~cm}$ de 4,70 m de long chacun. Textes composés en caractère Didot, tirés en offset sur Moulin du Gué 270 g. en 2 couleurs par le Groupe Prenant (emboîtage).

(c) FMA

Françoise Maréchal-Alligand traite le titre de la plupart des livres comme une iconographie à part entière: "J'essaie de traduire son sens en signe pour accentuer sa résonance. Pour La pomme et ses pépins, je me suis inspirée des ceuvres typographiques de Kurt Schwitters découvertes dans sa rétrospective au Centre G. Pompidou en 2014. »

La pomme et ses pépins (2016) (Fig. 14) ${ }^{12}$. Après son séjour à New York d'où il ramène de nombreuses photographies, Bernard Alligand envoie la maquette à Michel Butor en proposant des œuvres composées de photographies retouchées et imprimées en numérique sur support peint. Une technique particulière développée par l'artiste et donnant un aspect velouté au noir, comme dans Carré des météores (2013). «Dans les manuscrits de La pomme et ses pépins, Michel a eu l'idée d'alterner les vers en bicolore, déjà utilisé pour un poème bilingue dans les années 80. J'ai repris cette ingénieuse idée pour l'édition.» 
Figure 14. Michel Butor et Bernard Alligand, La pomme et ses pépins (2016).

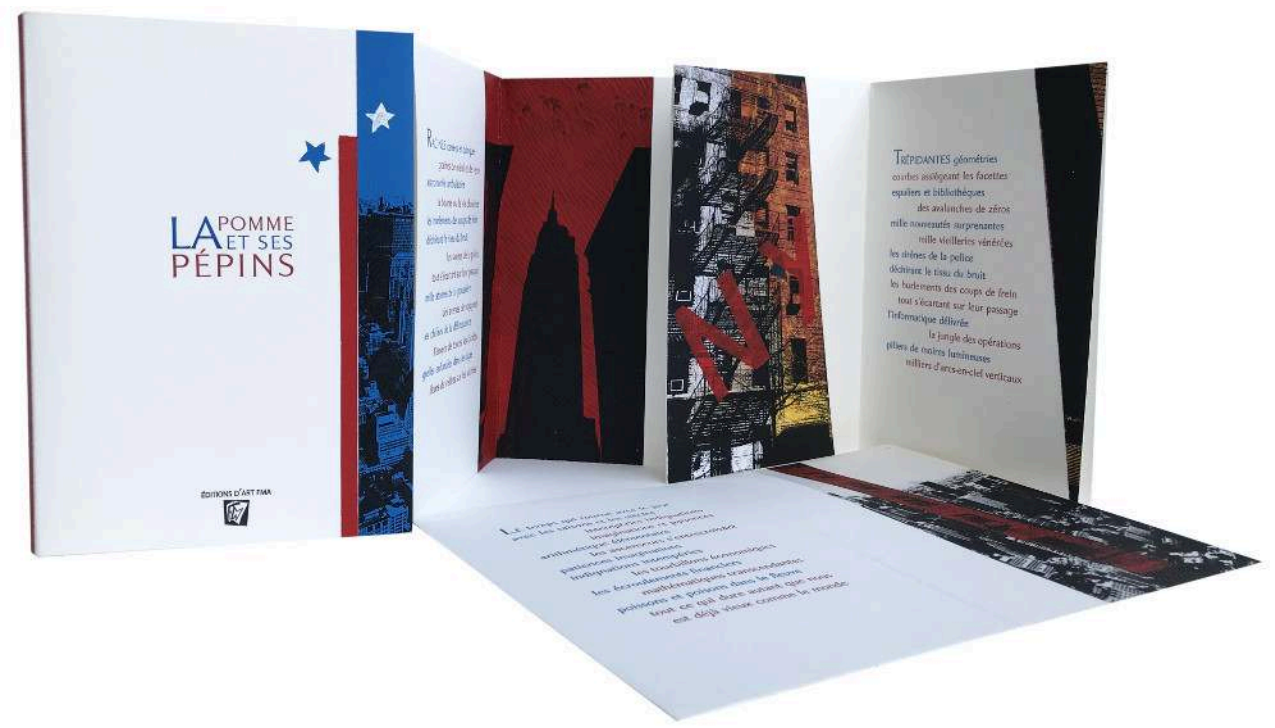

Poème inédit accompagné d'œuvres originales : lettrines, photographies numérisées, retouchées, imprimées sur papier peint par l'artiste, calque, rehaut de gouache, pochoir, découpes et collage. Édition originale à 45 ex. numérotés, signés par l'auteur et l'artiste. Livre en double feuillet, form. 16,5x $12,5 \mathrm{~cm}, 18$ p. plus couverture. Texte composé à la main en caractère Gauthier, tiré en deux couleurs sur Vélin BFK Rives 250 g. par l'Atelier du Livre d'art de l'Imprimerie nationale (emboîtage).

(c) FMA

\section{Vidéos des lectures et feuilletages}

Si elle cultive l'exclusivité, à destination d'une clientèle de collectionneurs et de bibliothèques publiques francophones, Françoise Maréchal-Alligand cherche à faire rayonner ses livres plus largement : «Cela peut sembler paradoxal mais je souhaite que tout le monde ait accès à ces livres merveilleux. Les bibliothèques et les médiathèques attachent de plus en plus d'importance à la médiation de leur collection patrimoniale. Elles créent des passerelles entre les arts, comme à Caen ou à Avignon. J'ai à cour de leur faciliter cette ouverture vers leurs publics. "L'éditrice réalise et met en ligne sur le site editionsdartfma.com et la chaîne YouTube les feuilletages des livres d'artistes ainsi que des lectures par les poètes eux-mêmes: "Le texte prend le relief de la sonorité et de la musicalité. Kenneth White donne deslectures théâtrales qui nous immergent dans son poème.»

Dans Les derniers jours d'Audubon (2015), il raconte comment l'ornithologue et grand peintre naturaliste, en quête d'oiseaux, finit par disparaitre dans le brouillard du Grand-Nord (Fig. 15). Le grand rassemblement à Geographic Harbor (2017) imagine un congrès de scientifiques aux titres ronflants qui s'échangent leurs trouvailles, surpris par la fonte d'un glacier : "Les discours se perdent en circonvolutions. Pendant ce temps, la nature s'exprime et le glacier fond inexorablement. "(Fig. 16) Dans le troisième livre En Scandinavie réalisé en 2019, Kenneth White introduit dans la mise en scène de sa lecture le tambour du peuple Saami (Fig. 17) ${ }^{13}$. 
Figure 15. Kenneth White et Bernard Alligand, Les derniers jours d'Audubon (2015).

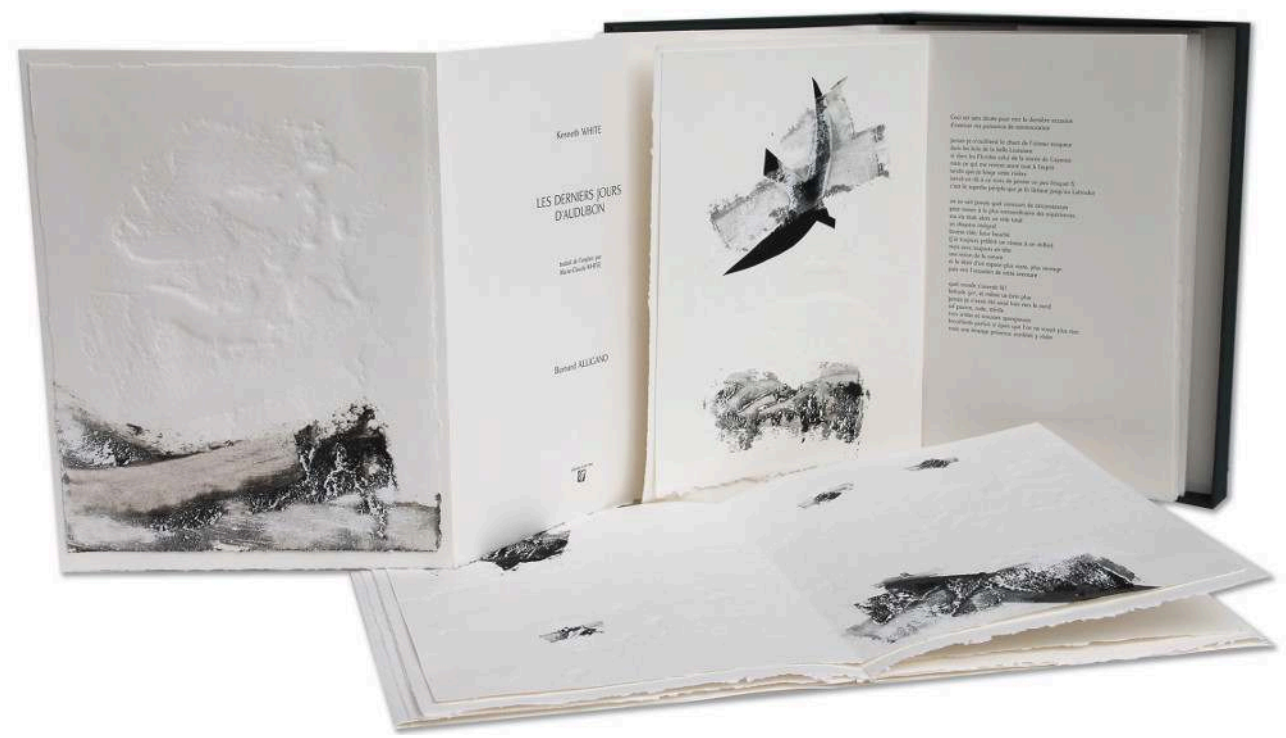

Prose inédite accompagnée d'œuvres originales : estampage selon la technique de gravure au carborundum. Rehaut de sable noir récolté en Islande par l'artiste, collage, apport de matière argentée et acrylique blanche. Édition originale à 45 ex. numérotés, signés par l'auteur et l'artiste. Livre en double feuillet, form. $32,5 \times 25 \mathrm{~cm}, 24$ p. plus couverture. Texte composé à la main en caractère Gauthier, tiré sur Vélin BFK Rives 250 g. et 300 g. pour la couverture par l'atelier du Livre d'art de I'Imprimerie nationale (emboîtage).

(c) FMA

Figure 16. Kenneth White et Bernard Alligand, Le grand rassemblement à Geographic Harbor (2017).



Prose inédite accompagnée d'œuvres originales : gravures au carborundum, estampage de sable noir, illustrations et photographies numérisées, impressions numériques, peinture acrylique, aquarelle. Édition originale à 30 ex. numérotés, signés par l'auteur et l'artiste. Leporello, form. $25 \mathrm{~cm}$, déplié 5,20 $m$ de long. Texte composé en caractère Didot, tiré en offset sur Moulin du Gué 270 g. en 2 couleurs par le Groupe Prenant (emboîtage).

(c) FMA 
Figure 17. Kenneth White et Bernard Alligand, En Scandinavie (2019).

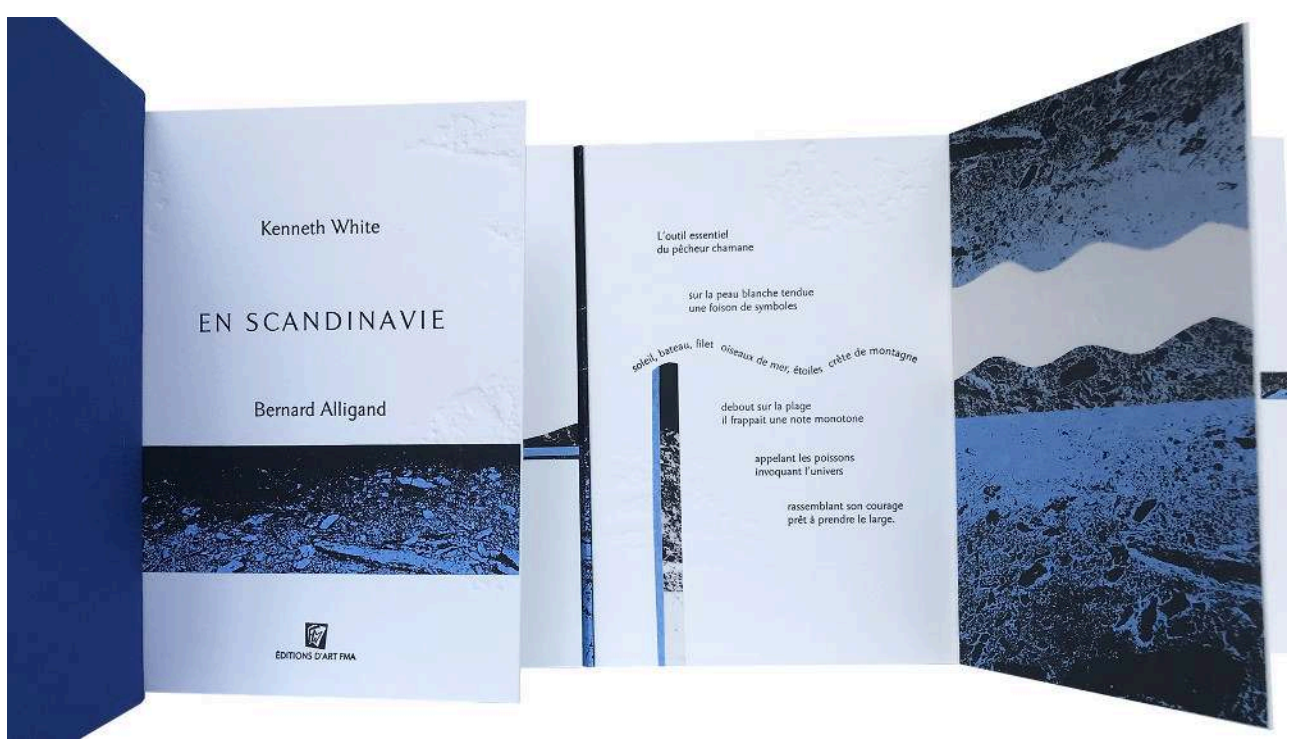

Recueil de 3 poèmes inédits accompagnés d'œuvres originales : photographies retouchées de minéraux, roches, numérisées et imprimées sur papier bleu, calque, découpes et collage. Estampage selon la technique de gravure au carborundum. Édition originale à 30 ex. numérotés, signés par l'auteur et l'artiste. Leporello, form. plié $12,5 \times 16,5 \mathrm{~cm}$, 18 volets plus rabat. Texte composé à la main en caractère Gauthier, tiré sur Vélin BFK Rives $250 \mathrm{~g}$. par l'atelier du Livre d'art de l'Imprimerie nationale (emboîtage).

(c) FMA

Chaque auteur a sa façon singulière de lire son texte. Michel Butor pose sa voix et prend soin de bien articuler : "Michel m'a dit un jour que sa mère était sourde, c'est pourquoi il avait un débit de parole lent et distinct pour qu'elle lise sur ses lèvres." Quant à Régine Detambel, l'exploratrice des vertus thérapeutiques de la lecture et de l'écriture a pris autant de plaisir à faire vivre ses poèmes à voix haute qu'à les écrire. Bernard Noël, quant à lui, adopte délibérément un ton sans emphase pour lire Trajet de l'oiseau (2018). "Georges Brassens disait : il faut que mes chansons aient l'air d'être parlées... il ne faut pas qu'aux moyens d'artifices musicaux, je détourne l'attention du texte. Bernard Noël adopte un ton neutre pour que l'on s'attache essentiellement au sens du poème. » (Fig. 18) ${ }^{14}$ 
Figure 18. Bernard Noël et Bernard Alligand, Trajet de I'oiseau (2018).

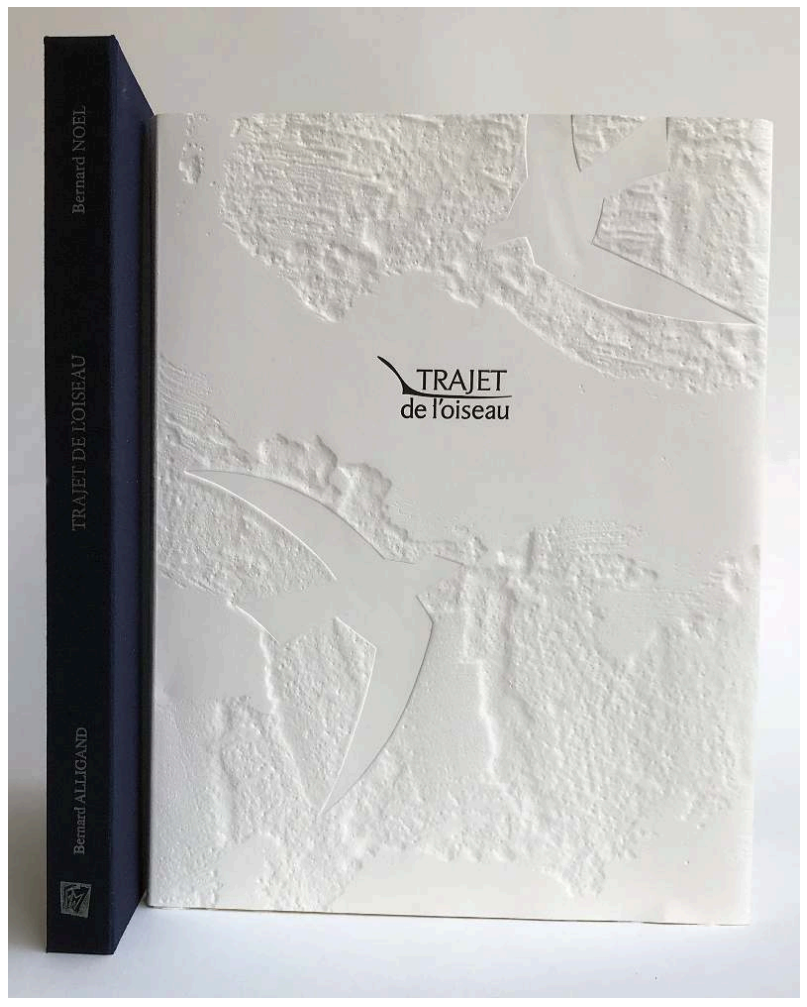

Poème inédit accompagné d'œuvres originales : estampage selon la technique de gravure au Carborundum à l'atelier Pasnic. Rehaut de sable noir récolté en Islande par l'artiste, collage, apport de matière argentée et acrylique blanche. Édition originale à 30 ex. numérotés, signés par l'auteur et l'artiste. Livre en double feuillet, form. $32,5 \times 25 \mathrm{~cm}, 24$ p. plus couverture. Texte composé à la main en caractère Gauthier, tiré sur Vélin BFK Rives $250 \mathrm{~g}$. et $300 \mathrm{~g}$. pour la couverture par l'atelier du Livre d'art de l'Imprimerie nationale (emboîtage).

(c) FMA

Mais il y a aussi le timbre radiophonique de la voix, enveloppante, qui nous immerge dans le sujet du texte. C'est le cas des lectures de Un dessein de beauté (2018) de Philippe Delaveau ou encore de Nature céleste (2019) de Jean-Pierre Geay (Fig. 19 et 20) ${ }^{15}$. 
Figure 19. Philippe Delaveau et Bernard Alligand, Un dessein de beauté (2018).

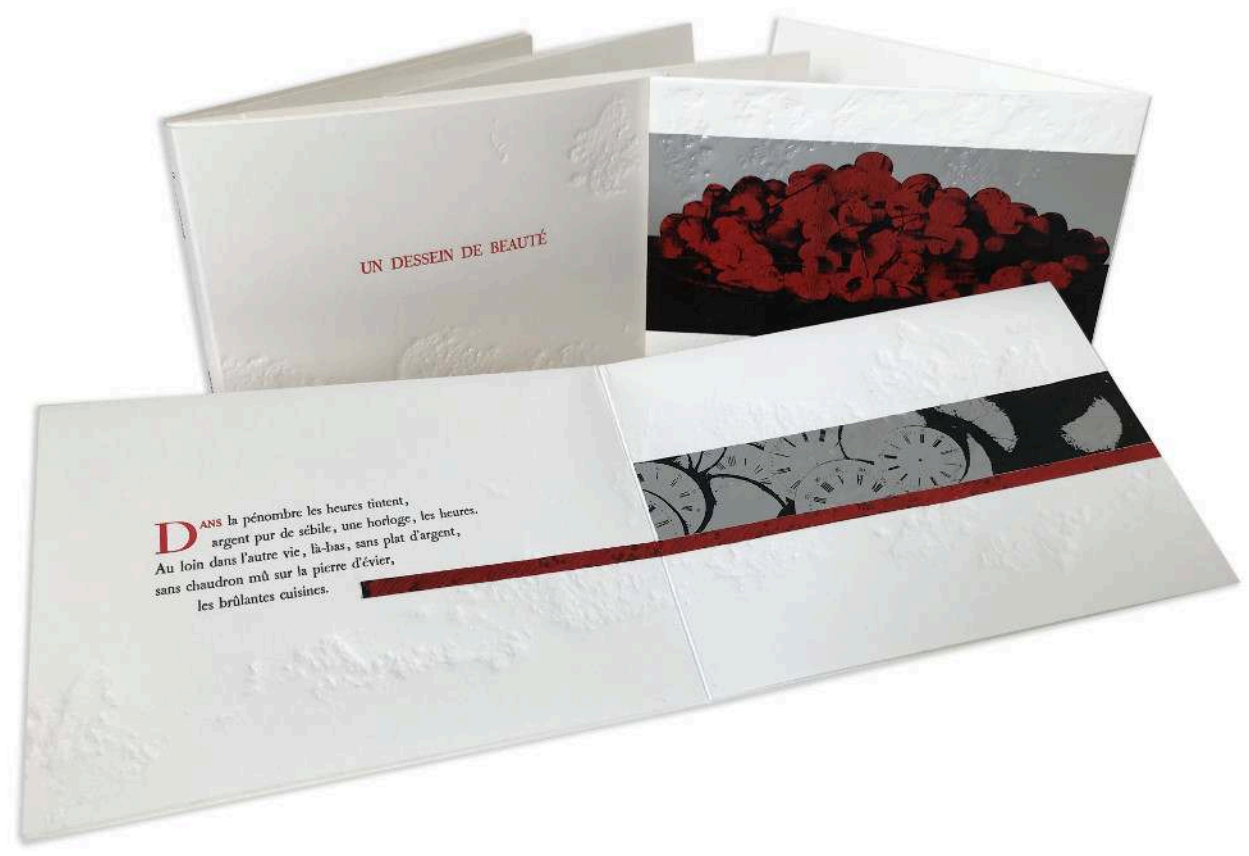

Poème inédit accompagné d'œuvres originales : détails de natures mortes issues de tableaux du XVIle siècle photographiées, numérisées, retouchées, tirées sur papier de différentes textures. Estampage selon la technique de gravure au carborundum. Édition originale à 45 ex. numérotés, signés par l'auteur et l'artiste. Livre en double feuillet, form. $12,5 \times 16,5 \mathrm{~cm}$, 12 p. plus couverture. Texte composé à la main en caractère Luce, tiré sur Vélin BFK Rives $250 \mathrm{~g}$. par l'atelier du Livre d'art de l'Imprimerie nationale (emboîtage).

(c) FMA 
Figure 20. Jean-Pierre Geay et Bernard Alligand, Nature céleste (2019).

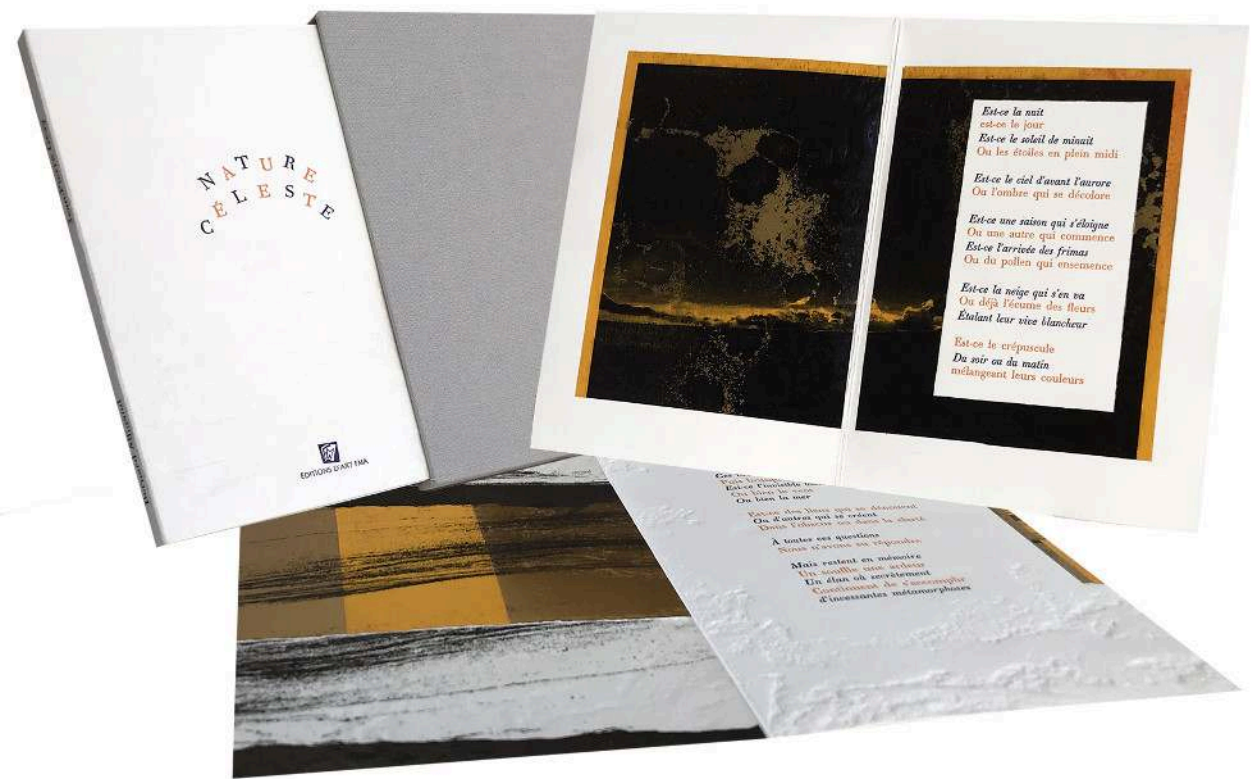

Poème inédit accompagné d'œuvres originales : photographies retouchées de paysages et végétaux, numérisées et imprimées sur papier doré, calque, peintures, découpes et collage. Estampage selon la technique de gravure au carborundum. Édition originale à 30 ex. numérotés, signés par l'auteur et l'artiste. Livre en feuillet, form. $12,5 \times 16,5 \mathrm{~cm}, 12$ p. plus couverture. Texte composé à la main en caractère Marcellin-Legrand, tiré en 2 couleurs bleu et jaune d'or sur Vélin BFK Rives $250 \mathrm{~g}$. par l'Atelier du Livre d'art de l'Imprimerie nationale (emboîtage).

(c) FMA

\section{Perspectives et acquisitions des ouvrages}

Les éditions d'art FMA continuent leur épopée avec deux nouvelles éditions originales.

Le miroir de personne de Lionel Ray et Bernard Alligand (Fig. 21) ${ }^{16}$. Aragon fut le premier à reconnaître son talent littéraire. Lionel Ray, écrivain et essayiste, est aussi l'un des plus grands poètes français. "Si je n'étais pas écrivain, je serais annaliste ou horloger. Je m'occuperais du temps, dont nul ne sait d'où il vient, ni ce qu'il est. » Généreux et inventif dans ses recherches d'effets de matière, l'artiste peintre Bernard Alligand sublime ce recueil de quatre poèmes de compositions sensibles et spectaculaires. 
Figure 21. Lionel Ray et Bernard Alligand, Le miroir de personne (2020).

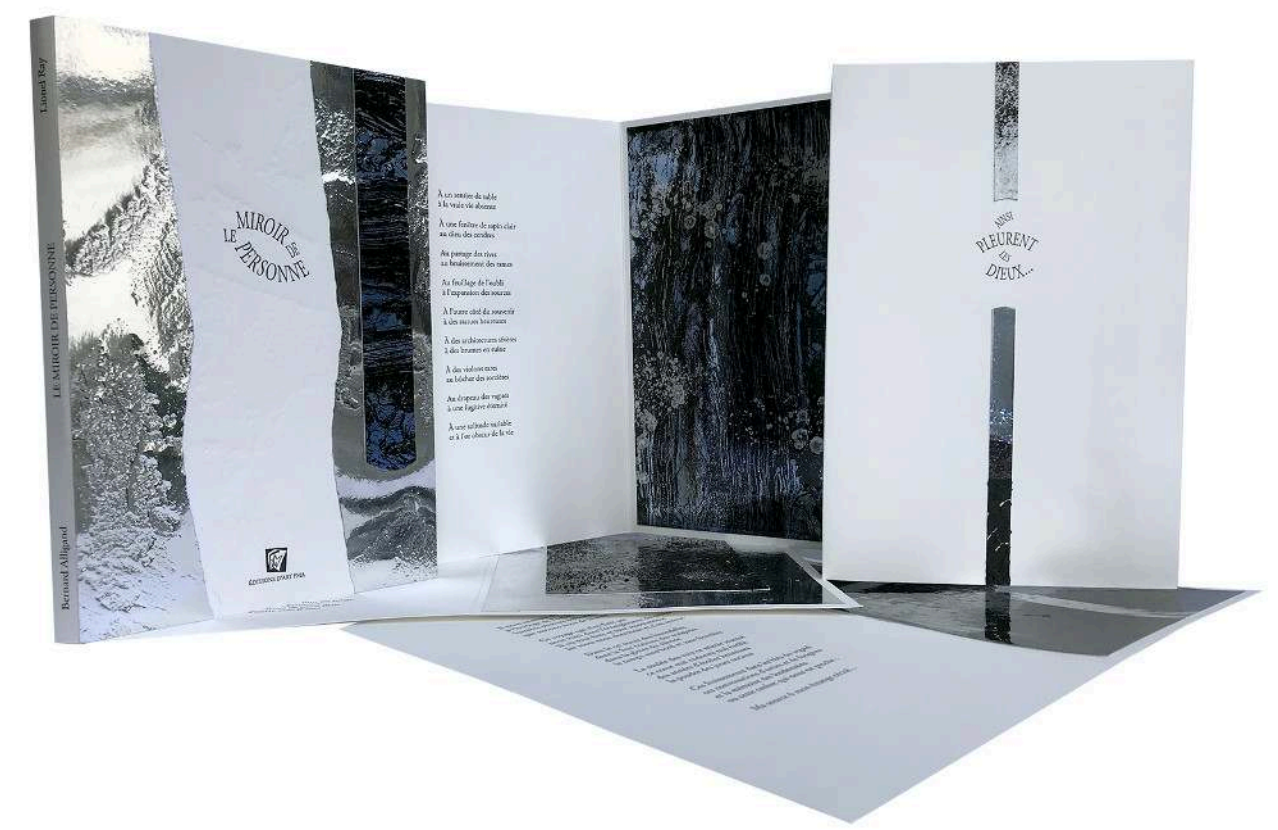

4 poèmes inédits accompagnés d'œuvres originales : sujets photographiés, numérisés, retouchés, imprimés sur papier métallisé. Découpes et collages. Estampage selon la technique de gravure au carborundum, rehaut de poudre argentée, mélange de sable et résine. Édition originale à 30 ex. numérotés, signés par l'auteur et l'artiste. Livre en feuille, form. $16 \times 24 \mathrm{~cm}, 24$ p. plus couverture. La maquette et les dessins (titre, faux-titre et têtes de chapitre) ont été réalisés par l'éditrice. Texte composé en caractère Garamond romain tiré sur BFK Rives blanc $250 \mathrm{~g}$. sur les presses typographiques de l'Atelier d'art des Montquartiers à Issy-les-Moulineaux (emboîtage).

(c) FMA

41 Une pierre - Klöpp de Sigurður Ingólfsson et Bernard Alligand est paru en janvier 2021 (Fig. 22). Docteur en Lettres Modernes de l'Université Paul Valéry à Montpellier, auteur d'une thèse sur La théologie négative dans la poésie d'Yves Bonnefoy, Sigurður Ingólfsson est un des poètes islandais francophones les plus aimés. 
Figure 22. Sigurður Ingólfsson et Bernard Alligand, Une pierre - Klöpp (2021).

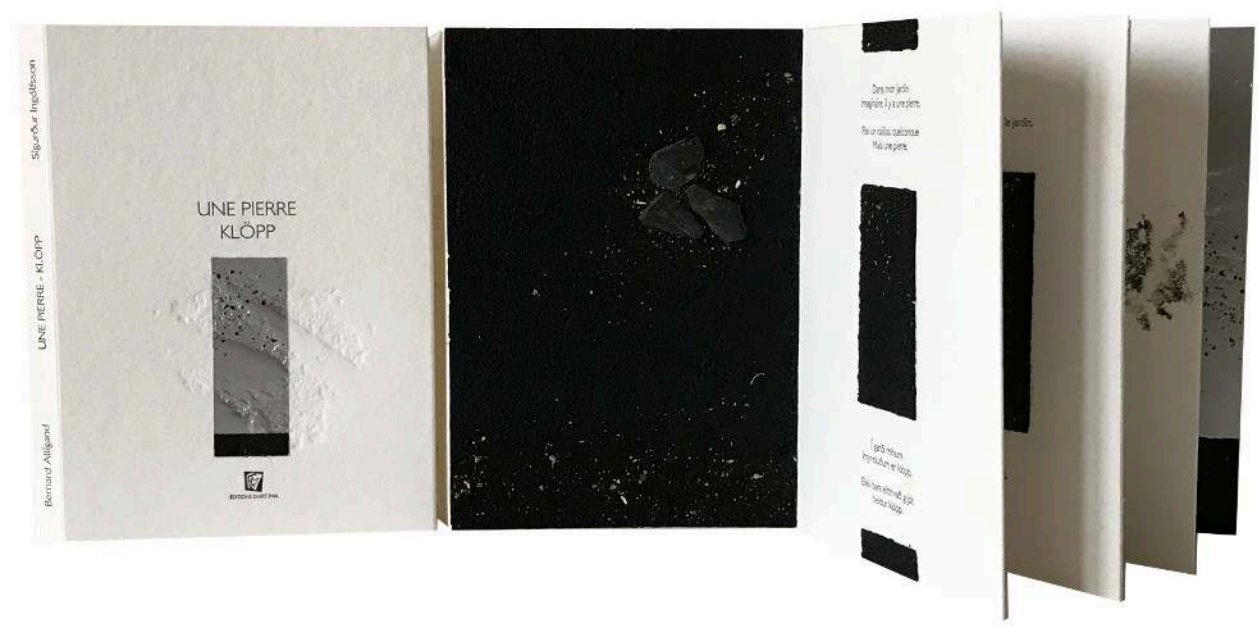

Poème inédit français/islandais accompagné d'œuvres originales : gravures au carborundum, collage de papier métallisé, estampage de sables noirs et beiges, collage de fragments d'ardoise, peinture et rehaut de matières mixtes. Édition originale à 30 ex. numérotés, signés par l'auteur et l'artiste. Leporello form. plié $17 \times 12 \mathrm{~cm}, 10$ p. plus couverture. Texte composé en caractère LondonMM tiré sur Moulin du Gué $270 \mathrm{~g}$. à I'Atelier d'art des Montquartiers à Issy-les-Moulineaux (emboîtage)

(c) FMA

Cette année, trois nouvelles éditions sont en cours d'élaboration. Françoise Maréchal-Alligand renouvelle sa collaboration avec Lionel Ray et continue à diversifier sa collection avec de nouveaux auteurs : Marc Alyn, écrivain et poète. Il reçoit de nombreux prix pour sa poésie: MaxJacob, Guillaume-Apollinaire, grand prix de la poésie de l'Académie française, de la SGDL, de Goncourt... et Alain Freixe poète, lauréat du prix Louis-Guillaume en 2000.

Aujourd'hui, près d'une vingtaine d'auteurs ont participé à la collection des Éditions d'art FMA. Françoise Maréchal-Alligand prépare de nouveaux projets d'envergure en associant plusieurs artistes, développe ses éditions dans les pays francophones et aux États-Unis, et promeut ses éditions par des rencontres-expositions et grâce aux outils numériques.

Les éditions d'art FMA sont visibles dans de nombreuses institutions en France et dans les pays francophones. La vente des ouvrages se fait par les librairies-galeries spécialisées, dont Claude et Paul Blaizot (Paris VIII) Arenthon (Paris $\mathrm{VI}^{2}$ ) Laure Matarasso (Nice) mchampetier.com (Cannes).

La fourchette de prix d'un livre d'artiste se situe entre $500 €$ et $1500 €$ TTC. Pour en savoir plus n'hésitez pas à contacter l'éditrice : editionsdartfma@gmail.com et vous rendre sur le site https://www.editionsdartfma.com 


\section{NOTES}

1. Le site des éditions FMA contient de nombreuses vidéos de présentation et lecture de ses œuvres. Voir https://www.editionsdartfma.com/la-restauration-du-corps-feminin (page consultée le 10 mai 2021).

2. Voir https://www.editionsdartfma.com/zone-grise (page consultée le 10 mai 2021).

3. Voir https://www.editionsdartfma.com/le-ring_(page consultée le 10 mai 2021).

4. Voir https://www.editionsdartfma.com/terre-d-ombre-brulee (page consultée le 10 mai 2021).

5. Voir https://www.editionsdartfma.com/ravigote_(page consultée le 10 mai 2021).

6. Voir https://www.editionsdartfma.com/rituel-des-sens (page consultée le 10 mai 2021).

7. Voir https://www.editionsdartfma.com/ruines-d-avenir (page consultée le 10 mai 2021).

8. Voir https://www.editionsdartfma.com/la-dame-a-la-licorne (page consultée le 10 mai 2021).

9. Voir https://www.editionsdartfma.com/hexagones-en-desarroi (page consultée le 10 mai 2021).

10. Voir https://www.editionsdartfma.com/rivage-de-pount (page consultée le 10 mai 2021).

11. Voir https://www.editionsdartfma.com/toros (page consultée le 10 mai 2021).

12. Voir https://www.editionsdartfma.com/la-pomme-et-ses-pepins (page consultée le 10 mai 2021).

13. Voir https://www.editionsdartfma.com/les-derniers-jours-d-audubon, https:// www.editionsdartfma.com/le-grand-rassemblement-a-geographic et https:// www.editionsdartfma.com/en-scandinavie (pages consultées le 10 mai 2021).

14. Voir https://www.editionsdartfma.com/trajet-de-l-oiseau (page consultée le 10 mai 2021).

15. Voir https://www.editionsdartfma.com/un-dessein-de-beaute et https:// www.editionsdartfma.com/nature-celeste (pages consultées le 10 mai 2021).

16. Voir https://www.editionsdartfma.com/le-miroir-de-personne (page consultée le 10 mai 2021). 


\section{AUTEUR}

\section{FRANÇOISE MARÉCHAL-ALLIGAND}

Françoise Maréchal-Alligand est publicitaire et éditrice française née en 1959 à Paris. Après des études de communication et en parallèle de son activité professionnelle en entreprise où elle exerce différents métiers de communication (publicité, marketing direct, éditorial, on et off line), elle s'intéresse à l'édition de livres de dialogue rares et précieux où se mêlent poésies inédites et peintures originales. De ses rencontres avec les auteurs et artistes contemporains, elle fonde les Éditions d'art FMA en 2008. Elle définit sa ligne éditoriale en s'inscrivant à contre-courant du monde numérique en plein essor et participe à son échelle à la sauvegarde des métiers traditionnels du livre et de la création contemporaine tout en ouvrant la médiation de ses éditions originales à petit tirage au plus grand nombre par le biais de vidéos disponibles sur Internet. Elle publie des livres d'artiste avec la participation de nombreux poètes, Michel Butor, Gaston Puel, Jean-Pierre Geay, Robert Marteau, Bernard Noël, Philippe Delaveau, Antoine Emaz, Régine Detambel, Lionel Ray... et collabore avec les artistes, Bernard Alligand, Patricia Erbelding, Gérard Eppelé, Julius Baltazar, Anne Walker, Bertrand Dorny... Les éditions d'art FMA figurent dans de nombreux Fonds patrimoniaux en France et à l'étranger, dans de prestigieuses collections de bibliophiles et auprès d'amateurs de beaux livres. 